\title{
Analisa Pengaruh Perubahan Penggunaan Lahan terhadap DAS Batang Kuranji dengan Menggunakan Model Soil and Water Assessment Tool (SWAT)
}

\section{Analysis of The Effect of Change in Land Use on the Batang Kuranji River Basin Using Soil and Water Assessment Tool (SWAT) Models}

\author{
Annisa Fitriana Definnas, Rozy Fairuzza Reyandal, Elvi Roza Syofyan \& Wisafri \\ Jurusan Teknik Sipil Politeknik Negeri Padang Kampus Limau Manis Padang \\ Telp. 0751-72590 Fax. 0751-72576 \\ Email : annisafitrianadefinnas@gmail.com; syofyan_er@yahoo.co.id
}

\begin{abstract}
Batang Kuranji is one of six rivers that flow in the city of Padang, and is the main source of water for residents of Padang City to meet the raw water which is then processed into clean water and the needs of Mt. Nago irrigation water. The increase in population causes the population to move to a higher area (green zone). Batang Kuranji watershed has experienced a reduction in the area of forest land due to changes in land use activities by the population movement. As a result, land that was not watertight at first became watertight, the mainstay discharge or expected discharge is always available, always increasing during the rainy season and decreasing during the dry season. This study was conducted to determine the extent of land use change in the Batang Kuranji watershed, also to determine the main discharge that occurred in 2009, 2011, and 2017 using the Soil and Water Assessment Tool (SWAT) model. The analysis consists of four processes, namely watershed delineation, formation of a Hydrologic Response Unit (HRU), formation of climatological data, and finally the simulation process. HRU analysis results obtained by Batang Kuranji watershed into 9 sub-watersheds, the dominant HRU is protection forest by $62 \%$, soil type with depth (solum) level A and B, runoff coefficient of 0.3 and NS value obtained by 0.6. This shows that the SWAT model can predict the hydrological process in the upstream Batang Kuranji watershed. The most influential land use on surface runoff is land use for settlement.
\end{abstract}

Key words : Land Use, SWAT, HRU, mainstay discharge, DAS Batang Kuranji

\section{PENDAHULUAN}

Meningkatnya kuantitas penduduk memberikan pertumbuhan yang signifikan, yang mana menyebabkan kebutuhan tataguna lahan juga meningkat. Peningkatan kebutuhan tataguna lahan ini mengakibatkan penurunan kualitas terhadap lingkungan. Hal ini akan memberikan dampak yang besar terhadap sistem hidrologi DAS. Meningkatnya pertumbuhan penduduk, maka semakin banyak pula lahan yang digarap dan ditata menjadi pemukiman, sektor industri, dan lainnya. Sungai yang mulanya dapat menampung air saat kondisi hujan, tidak mampu menampung air sehingga terjadi banjir, erosi, dan sedimentasi. Namun saat kondisi kering, kebutuhan airpun semakin sulit.

Karakteristik DAS dapat dihasilkan dari analisis satuan respon hidrologi (Hydrologic Response Unit/HRU). HRU merupakan satuan analisis hidrologi yang dibentuk berdasarkan jenis tanah, ketinggian dan lereng, geologi serta penutup lahan. Analisis HRU tersebut dapat menghasilkan fakta dan fenomena keruangan yang ada dalam lingkup 
hubungan antar subDAS. Perubahan HRU ini biasanya terjadi akibat berkembangnya suatu wilayah yang membutuhkan lahan untuk pemukiman maupun tutupan lahan lainnya.

Berdasarkan permasalahan di atas, maka penelitian ini dilakukan dan diteusuri dengan menggunakan simulasi permodelan Soil and Water Assessment Tool (SWAT). Model SWAT telah banyak mengkaji dampak pengunaan lahan suatu DAS terhadap hasil air, namun hasil simulasinya beragam. Penerapan model SWAT dalam skala DAS dengan input data yang cukup beragam dan bersifat kontinyu. Penelitian ini bertujuan untuk mengetahui besarnya pegaruh perubahan tataguna lahan terhadap aliran permukaan dan debit sungai pada DAS Batang Kuranji, juga mengetahui besaran spasial HRU pada masing-masing subDAS Batang Kuranji.

\section{METODOLOGI}

Daerah Aliran Sungai Batang Kuranji di sebelah Utara berbatasan dengan DAS Singkarak, di sebelah Timur dengan DAS Sumani, di sebelah Barat dengan DAS Batang Air Dingin dan Samudera Indonesia, di sebelah Selatan dengan DAS Batang Arau. Secara geografis, DAS Batang Kuranji terletak pada $0^{\circ} 48^{\prime}-0^{\circ} 56^{\prime}$ LS dan $100^{\circ} 21^{\prime}-100^{\circ} 33^{\prime}$ BT, dengan ketinggian 0-1.858 Mdpl. Sumber airnya berasal dari Sungai Padang Janiah, Sungai Padang Karuah dan Sungai Limau Manih. Luas DAS Kuranji sekitar 202,69 ha yang membentang pada wilayah administrasi Kota Padang dan Kabupaten Solok. Batang Kuranji mengalir dari hulu bukit barisan puncak Bukit Tinjau Laut dan bermuara ke pantai padang dengan panjang sungai utama 19,69 km, dan panjang total beserta seluruh anak sungainya sepanjang 840,419 Km.
SWAT adalah model hidrologi yang dikembangkan oleh Dr. Jeff Arnold untuk USDA Agricuture Research Service (ARS) pada tahun 1990an. SWAT dikembangkan untuk memprediksi dampak pengelolaan tanah terhadap air sedimen dan bahan kimia pertanian yang masuk ke sungai atau badan air pada suatu DAS dengan berbaga rupa tanah, penggunaan tanah dan kondisi pengelolaan pada waktu yang lama. SWAT merupakan model kejadian kontinyu untuk skala DAS yang beroperasi secara harian, bulanan, maupun tahunan dan dan dirancang untuk memprediksi dampak pengelolaan terhadap air, sedimen, dan kimia pertanian pada DAS yang tidak memiliki alat pengukuran. Model SWAT berbasis fisik, efisiensi secara komputerisasi, dan mampu membuat simulasi untuk jangka waktu yang panjang. Komponen utama model adalah iklim, tanah, tutpan lahan termasuk pola tanam dan pengelolaan tanaman, kelerengan, suhu, dan curah hujan. Dalam SWAT, DAS dibagi menjadi beberapa subbasin, yang kemudian dibagi lagi ke dalam unit respon hidrologi (Hydrologic Response Unit = HRU) yang memiliki karakteristik tutupan lahan, kelerengan, dan tanah yang homogen. hRU diditribusikan pada subbasin secara spasial dalam simulasi SWAT (Neitsch et al. 2005).

Dalam menjalankan setiap anaisis hidrologi, SWAT menggunakan neraca air sebagai dasar permodelan. Siklus hidrologi yang digunakan oleh SWAT dibagi menjadi dua, yaitu:

- Fase lahan yang mengatur jumlah air, sedimen, unsur hara, dan pestisida dalam pengisian saluran utama pada masing-masing subbasin. 
- Fase air yang berupa pergerakan air, sedimen, dan lainnya melalui jaringan sungai pada DAS menuju outlet. Skema fase lahan pada siklus hidrologi dan persamaan neraca air yang digunakan dalam model SWAT.

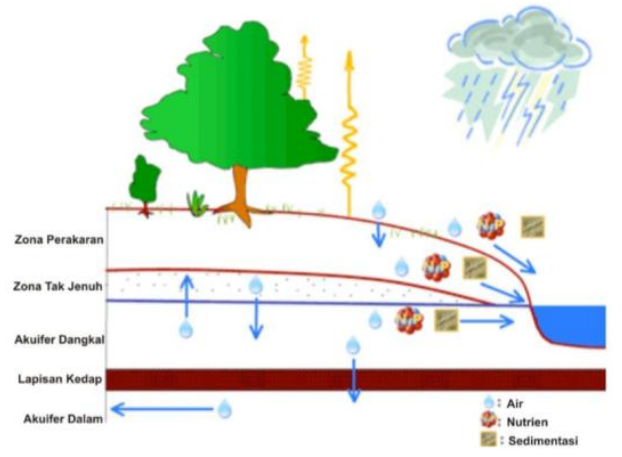

Gambar 1. Proses fase lahan pada siklus hidrologi (Neitsch et al, 2004)

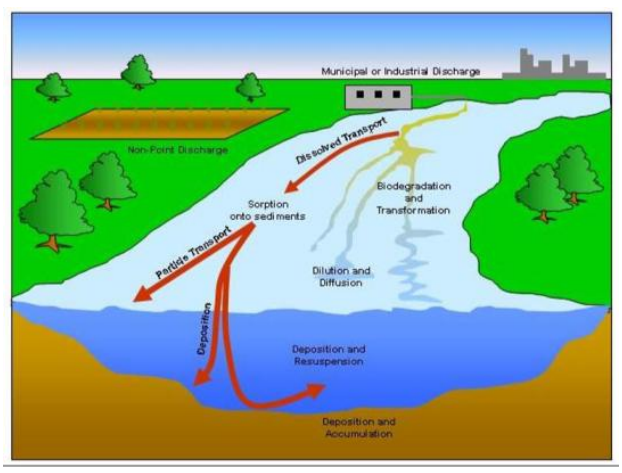

Gambar 2. Proses fase air berdasarkan model SWAT (Neitsch et al, 2005)

Model SWAT dapat digunakan untuk menemukan dampak perubahan penggunaan lahan terhadap kondisi hidrologi. Simulasi dari setiap seri data penggunaan lahan menunjukkan adanya dampak perubahan penggunaan lahan pada karakteristik hidrologi.

Untuk tahap analisis sendiri dilakukan dengan menginput data karakteristik tanah, iklim, dan curah hujan. Tahap yang pertama yaitu melakukan proses delineasi daerah observasi menggunakan peta DEM SRTM resolusi 30 meter yang diolah menggunakan perangkat lunak Map Windows/Microsoft.Net. Metode yang digunakan dalam proses delineasi adalah metode threshold, dimana besar kecil nilai threshold yang digunakan akan menentukan jumlah jaringan sungai yang terbentuk. Jadi, semakin besar nilai threshold yang dimasukkan, maka semakin kecil jumlah jaringan sungai yang terbentuk, begitupun sebaliknya.

Selanjutnya melakukan proses pembetunkan Hydrologic Response Unit (HRU). HRU mengambarkan pengaruh suatu wilayah terhadap faktor hidrologi yang terjadi pada wilayah tersebut, pembagian wilayah tersebut berdasarkan karakteristik tanah, tata guna lahan, dan kemiringan lahan. Input peta tanah dan penggunaan lahan harus dalam koordinas sitem UTM, dan dalam format raster. Selanjutnya faktor kemiringan yang digunakan dalam menentukan HRU dibagi dalam beberapa pembagian menurut yakni 5, 15, 25, sampai 40. Threshold dari persentase total luasan yang digunakan untuk landuse $(10 \%)$, jenis tanah $(5 \%)$, dan Slope (5\%) yang memiliki persentase luasan yang lebih kecil dari threshold yang ditentukan untuk diabaikan (Irsyad, 2011). Satuan yang digunakan dalam model SWAT ini adalah Satuan Peta Tanah (SPT) untuk menghitung pembagian wilayahnya.

Setelah satuan analisis terbentuk, HRU digabungkan dengan data iklim. Pembuatan basis data iklim dilakukan untuk membuat data generator iklim (weather generator data) terdiri atas 14 parameter input yang harus dihitung terlebih dahulu berdasarkan data iklim. Selain itu juga dibutuhkan pembuatan file input data curah hujan (rainfall data) tahun 2008 hingga 2017 yang berasal dari stasiun pengamatan Bendung Gunung Nago.

Terakhir tahap simulasi dan kalibrasi. Metode statistik yang digunakan dalam melakukan kalibrasi dan validasi 
adalah model koefisien determinasi $\left(\mathrm{R}^{2}\right)$ dan model efisiensi Nash-Sutcliffe (NS) yang direkomendasikan oleh The American of Civil Engineers (Ahl et al 2008 dalam Emiyati 2012). Persamaan model yang digunakan adalah persamaan sebagai berikut.

$$
\begin{aligned}
& R^{2}=\left[\frac{\sum_{i=1}^{n}\left(Q_{o b s, i}-\bar{Q}_{o b s, i}\right)\left(Q_{c a l, i}-\bar{Q}_{c a l, i}\right)}{\sqrt{\sum_{i=1}^{n}\left(Q_{o b s, i}-\bar{Q}_{o b s, i}\right)^{2}} \sum_{i=1}^{n}\left(Q_{c a l, ~}-\bar{Q}_{c a l, i}\right)^{2}}\right]^{2} \ldots
\end{aligned}
$$

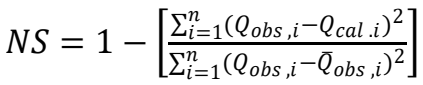

$$
Q_{o b s, i} \text { adalah debit observasi }
$$
( $\mathrm{m}^{3} /$ detik), $Q_{c a l, i}$ adalah debit hasil simulasi ( $\mathrm{m}^{3} /$ detik), $\bar{Q}_{c a l, i}$ adalah debit simulasi rata-rata $\left(\mathrm{m}^{3} /\right.$ detik), sedangkan $\bar{Q}_{o b s, i}$ adalah debit observasi rata-rata $\left(\mathrm{m}^{3} /\right.$ detik). Dalam kriterianya, simulasi dianggap baik jika nilai NS > 0.75, memuaskan jika $0.36<\mathrm{NS}<0.75$, namun kurang baik jika NS < 0.36 .

Setelah analisis permodelan SWAT dilakukan, hasil debit simulasi dibandingkan dengan menggunakan simulasi manual metode FJ. Mock, dimana metode ini sangat sering digunakan untuk daerah dengan curah hujan tinggi seperti Sumatera Barat, khususnya Batang Kuranji.

\section{HASIL DAN PEMBAHASAN} Analisa HRU

Pada analisa HRU, diperoleh kemiringan pada DAS Batang Kuranji dengan level kemiringan sebagai berikut.

- Agak datar : kemiringan 1-3\%

- Agak landai: kemiringan 3-8\%

- Bergelombang : kemiringan 8-15\%

- Berbukit kecil : kemiringan 15-25\%

- Agak curam : kemiringan 16-25\%

- Berbukit : kemiringan 25-40\%

- Pegunungan : kemiringan $>40 \%$

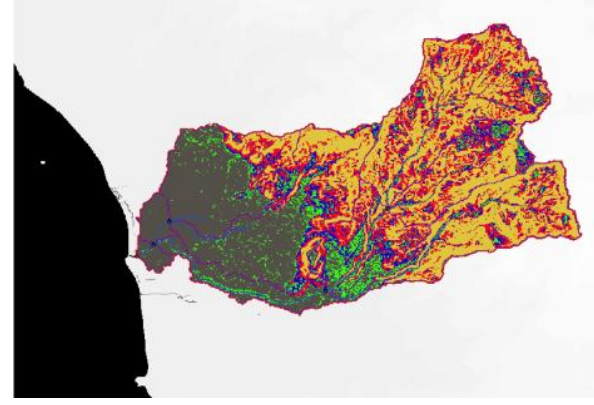

Gambar 3. Kemiringan DAS Batang Kuranji berdasarkan analisis HRU

Jenis batuan yang ada di daerah Batang Kuranji pada umumnya adalah batuan aluvium dan andesit pada solum yang dalam kelas A dan B. Jenis tanahnya beragam, yaitu gleisol, andosol, kambisol, dan lainnya dengan tekstur halus dan agak halus.

Hasil analisis cluster pada DEM SRTM ini diperoleh 9 sub DAS dengan luas area yang bervariasi. Berdasarkan gambar 4 terlihat bahwa subDAS yang mempunyai luas terbesar adalah subDAS 1 di Kelurahan Lambung Bukit dan yang terkecil adalah subDAS 6 di Ulak Karang.

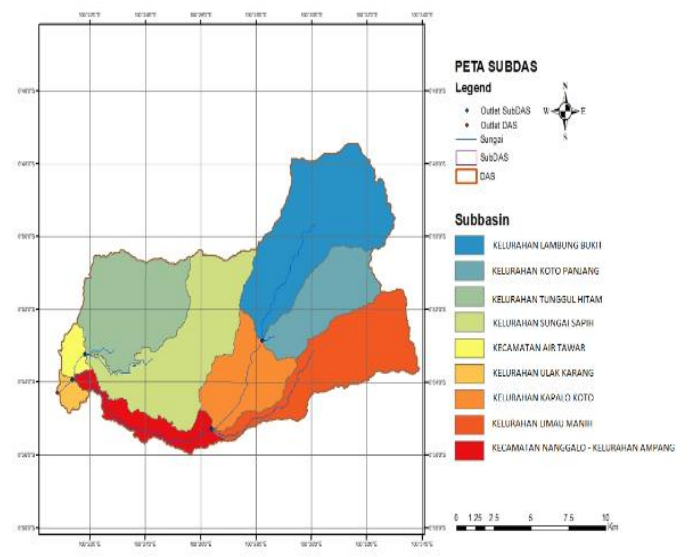

Gambar 4. Peta DAS Batang Kuranji berdasarkan analisis cluster DEM SRTM

\section{Klasifikasi Kelas Penggunaan Lahan}

Perubahan Hydrologic Response Unit (HRU) dapat diamati berdasarkan perubahan tutupan lahan, karena HRU merupakan tumpang tindih dari penutup lahan, lereng, dan karakteristik tanah. 
Perubahan penutup lahan yang terjadi pada suatu wilayah fenomenanya dapat diamati dengan menggunakan citra satelit multi waktu. Selain perubahan penutup lahan secara temporal, jumlah kelas saat klasifikasi juga akan mempengaruhi pola tutupan lahan. Pada penelitian ini digunakan dua tahap klasifikasi penutup lahan di DAS Batang Kuranji berdasarkan citra Landsat. Pada tahap ini, diperoleh 6 klasifikasi tataguna lahan di tahun 2009 seperti hutan lebat, hutan campuran, pemukiman, pertanian lahan kering campur semak, sawah, dan pertanian lahan kering. Sedangkan di tahun 2011 dan 2017 terjadi perubahan menjadi 7 klasifikasi tataguna lahan. Yang bertambah pada tahun tersebut adalah semak belukar.

Tabel 1. Perubahan tataguna lahan pada DAS Batang Kuranji tahun 2009, 2011, dan 2017

\begin{tabular}{|c|c|c|c|c|c|c|c|c|c|}
\hline \multirow{3}{*}{ Kelas Pentupp Lahan } & \multicolumn{3}{|c|}{ Luas (Ha) } & \multicolumn{6}{|c|}{ Perndahan Penulup Lahan } \\
\hline & \multirow{2}{*}{2009} & \multirow{2}{*}{2011} & \multirow{2}{*}{2017} & \multicolumn{2}{|c|}{$2009-2011$} & \multicolumn{2}{|c|}{$2011-2017$} & \multicolumn{2}{|c|}{$2009-2017$} \\
\hline & & & & $\mathrm{Ha}$ & $\%$ & Ha & $\%$ & $\mathrm{Ha}$ & $\%$ \\
\hline Hutan & 10744.7 & 11800.4 & 11798.1 & 1055.7 & 9.8 & $-2,3$ & 0.0 & 1053.4 & 9.8 \\
\hline Hitan campuran & 2688.4 & 406.4 & 403.9 & 2282.0 & 84.9 & 2.5 & 0.6 & 2284.6 & 85.0 \\
\hline Pemkiman & 967.5 & 1016.9 & 1059.7 & 49.4 & 5.1 & 42.8 & 4.2 & 92.2 & 9.5 \\
\hline Semak belukar & 0.0 & 1176.9 & 1170.7 & 1176.9 & 0.0 & -6.2 & .0 .5 & 1170.7 & 0.0 \\
\hline Pettanina han kan kering campur semak & 5003.3 & 50033 & 5002.0 & 0.0 & 0.0 & 1.3 & 0.0 & 1.3 & 0.0 \\
\hline Saxwh & 323.4 & 323.4 & 327.7 & 0.0 & 0.0 & 4.2 & 1.3 & 4.2 & 1.3 \\
\hline Pettanian lahan kering & 1219.1 & 1219.1 & 1219.9 & 0.0 & 0.0 & 0.8 & 0.1 & 0.8 & 0.1 \\
\hline
\end{tabular}

Berdasarkan hasil analisa, diperoleh klasifikasi perubahan tataguna lahan pada tahun 2009 sebanyak 6 kelas yang terdiri dari hutan lindung, hutan campuran, pemukiman, pertanian lahan kering campur semak, sawah, dan pertanian lahan kering. Sedangkan pada tahun 2011 dan 2017 terdapat penambahan tataguna lahan yaitu semak belukar. Ditinjau dari ketiga tahun tersebut, luas lahan yang paling dominan adalah hutan lahan kering primer, hal ini dikarenakan daerah tersebut masih didominasi oleh hutan. Namun, dilihat dari tahun 20092017 terjadi penurunan terhadap luas hutan akibat penggunaan lahan pada daerah hulu DAS Batang Kuranji tersebut. Laju perubahan tataguna lahan yang paling terbesar pada tahun 2009-2017 adalah pemukiman dan sawah. Hal ini bisa kita jadikan acuan dikarenakan daerah Batang Kuranji terdapat bendung Gunung Nago, pada tahun-tahun tersebut terjadi perluasan lahan untuk pertanian terutama sawah.

Perubahan tataguna lahan pada tahun 2009, 2011, 2017 ini tidak selalu linier, tetapi berfluktuatif seperti yang terjadi pada pemukiman, sawah, dan pertanian lahan kering. Untuk hutan lahan kering primer, terjadi kenaikan luas daerah di setiap tahunnya, karena daerah tersebut memang tidak ada terjadi aktivitas manusia. Untuk semak belukar, terjadi peningkatan luas, pada tahun 2009 tidak ada semak belukar. Namun pada tahun 2011 dan 2017 ditemukan semak belukar.

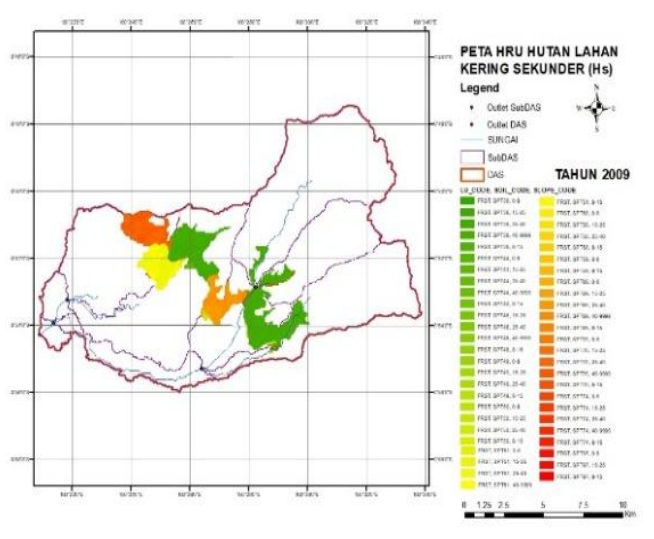

Gambar 5. HRU hutan campuran pada tahun 2009

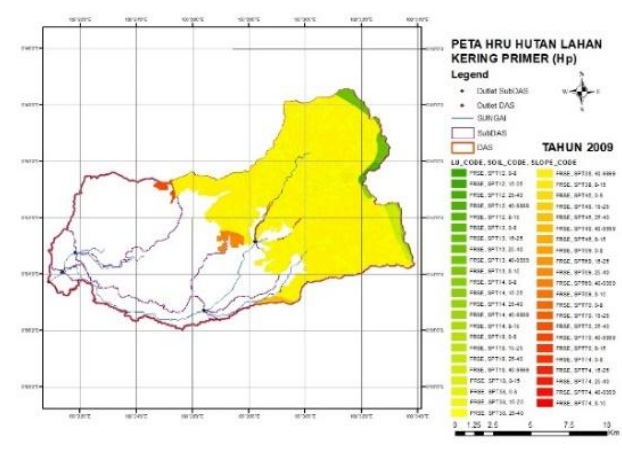

Gambar 6. HRU hutan lindung pada tahun 2009 


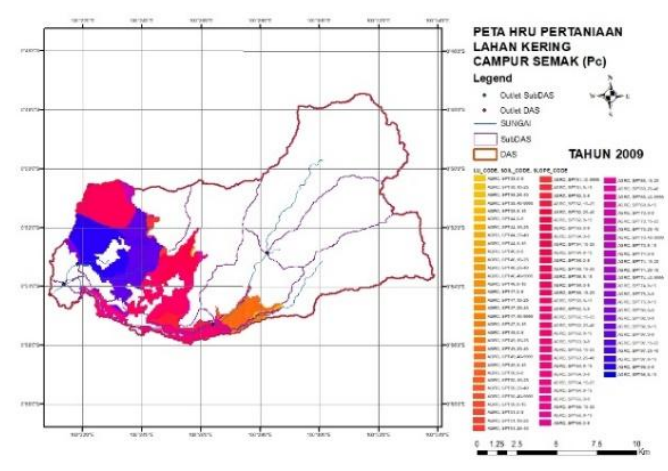

Gambar 7. HRU pertanian lahan kering campur semak pada tahun 2009

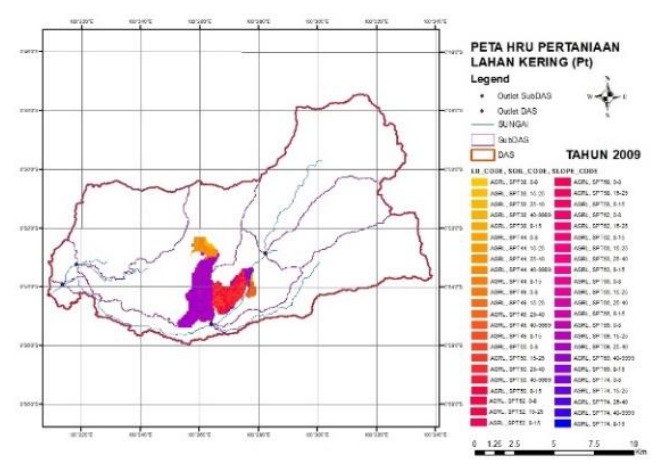

Gambar 8. HRU pertanian lahan kering pada tahun 2009

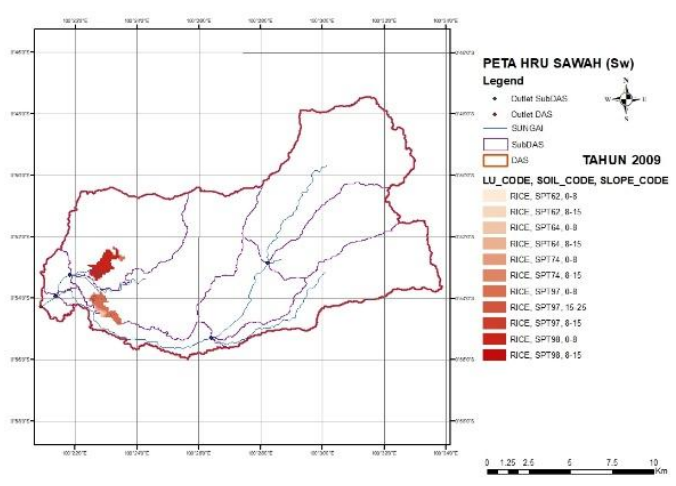

Gambar 9. HRU sawah pada tahun 2009

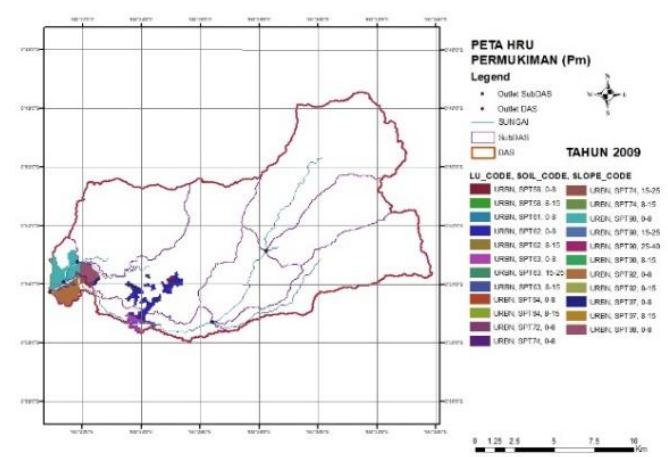

Gambar 10. HRU pemukiman pada tahun 2009
Berdasarkan gambar HRU pada tahun 2009 di atas, terlihat jelas DAS Batang Kuranji didominasi oleh hutan primer di bagian hulu DAS dan pertanian lahan kering campur semak di bagian hilir bendung Gunung Nago. Daerah hilir DAS yang mana daerah tersebut adalah Ulak Karang didominasi oleh pemukiman.

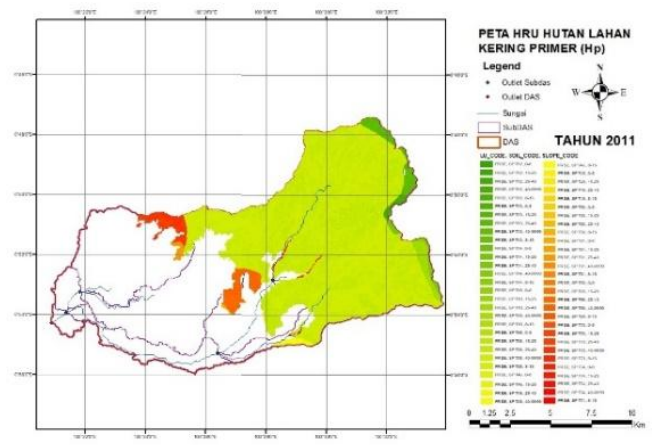

Gambar 11. HRU hutan lindung pada tahun 2011

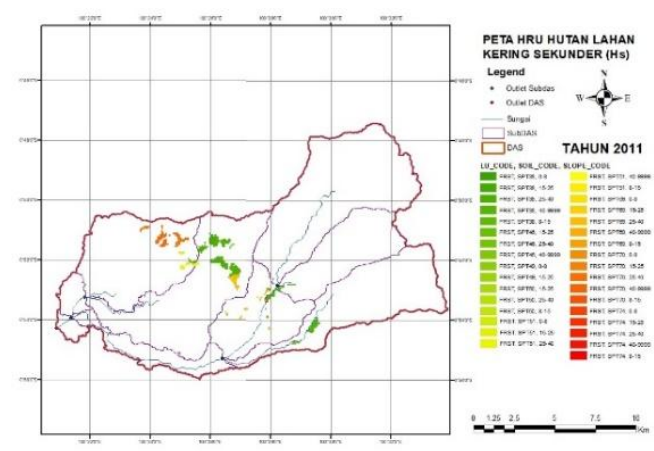

Gambar 12. Peta HRU hutan campuran pada tahun 2011

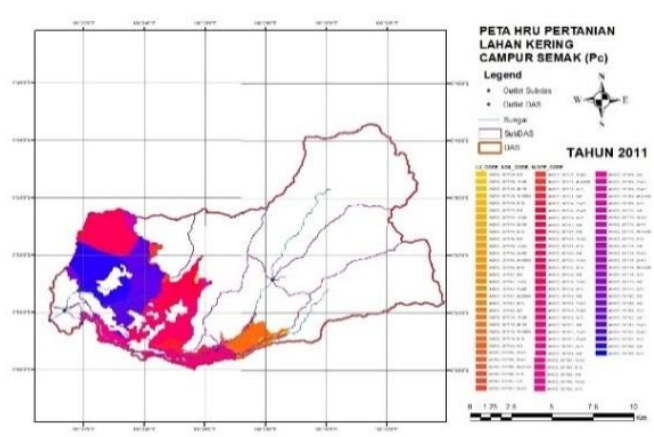

Gambar 13. Peta HRU lahan kering campur semak pada tahun 2011 


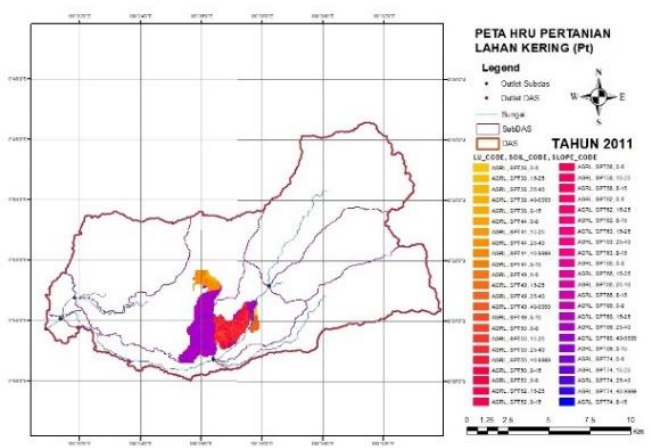

Gambar 14. Peta HRU pertanian lahan kering pada tahun 2011

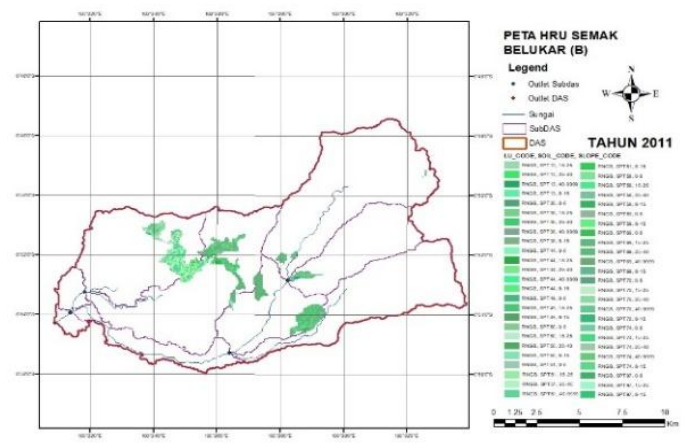

Gambar 15. Peta HRU semak belukar pada tahun 2011

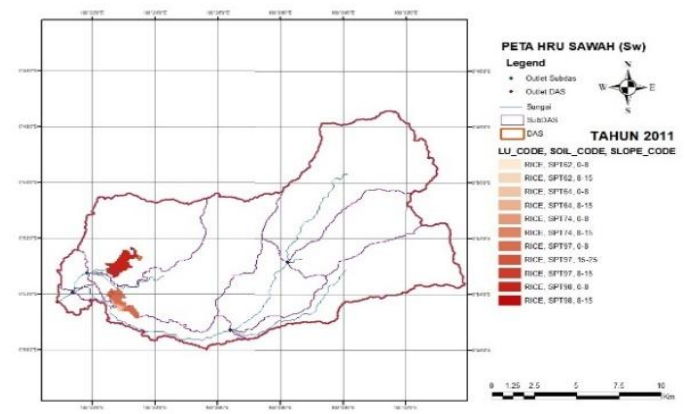

Gambar 16. Peta HRU sawah pada tahun 2011

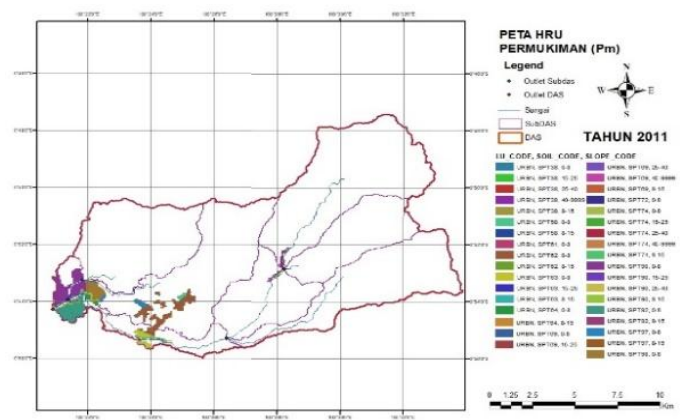

Gambar 17. Peta HRU pemukiman pada tahun 2011
Pada tahun 2011, perubahan tataguna lahan pada DAS Batang Kuranji tidak terlalu signifikan terhadap tahun 2009. Ini dikarenakan perubahan penggunaan lahan tidak terjadi begitu besar, sehingga terlihat sedikit perbedaan luas penutup lahan tahun 2009-2011. Namun pada tahun 2011 terdapat semak belukar di bagian hulu Bendung Gunung Nago, semak belukar terjadi akibat perubahan lahan hutan campur di bagian hulu Bendung Gunung Nago.

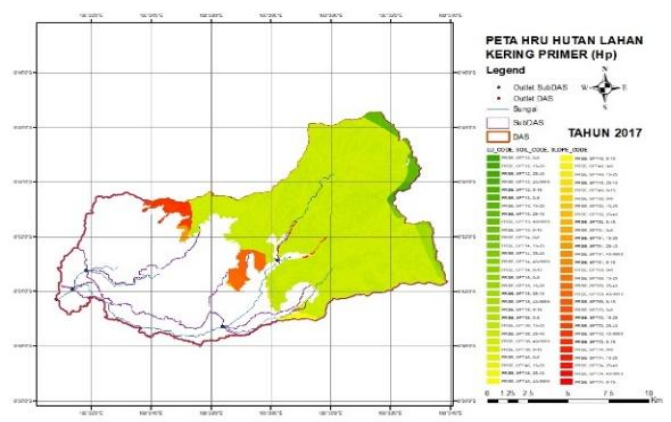

Gambar 18. Peta HRU hutan lindung pada tahun 2017

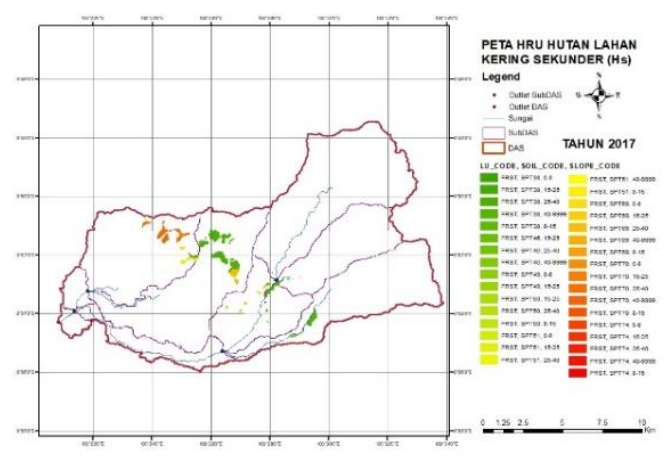

Gambar 19. Peta HRU hutan campuran pada tahun 2017

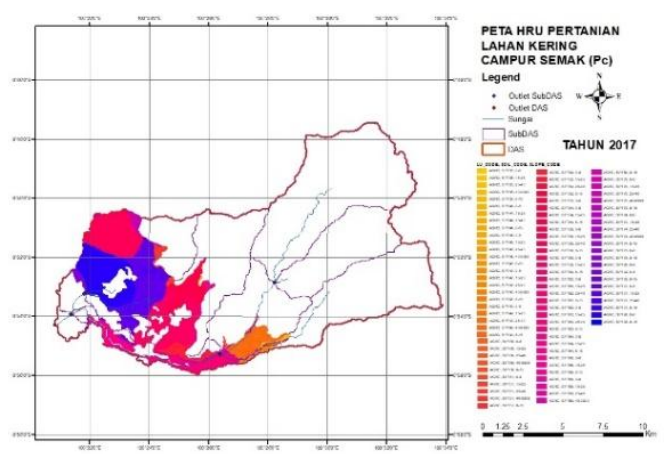

Gambar 20. Peta HRU pertanian lahan kering campur semak pada tahun 2017 


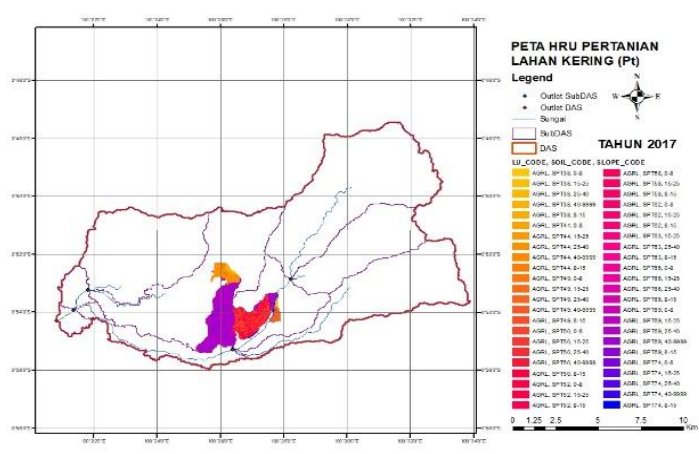

Gambar 21. Peta HRU pertanian lahan kering pada tahun 2017

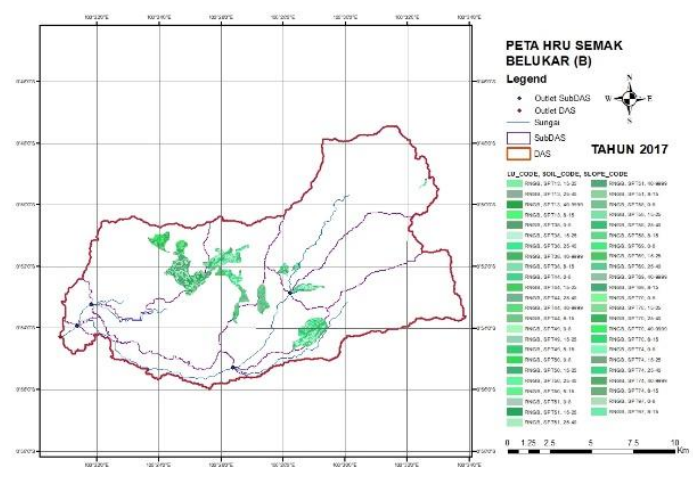

Gambar 22. Peta HRU semak belukar pada tahun 2017

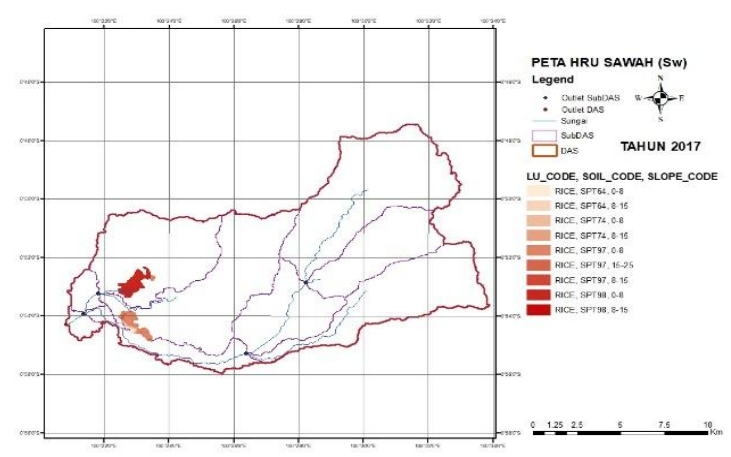

Gambar 23. Peta HRU sawah pada tahun 2017

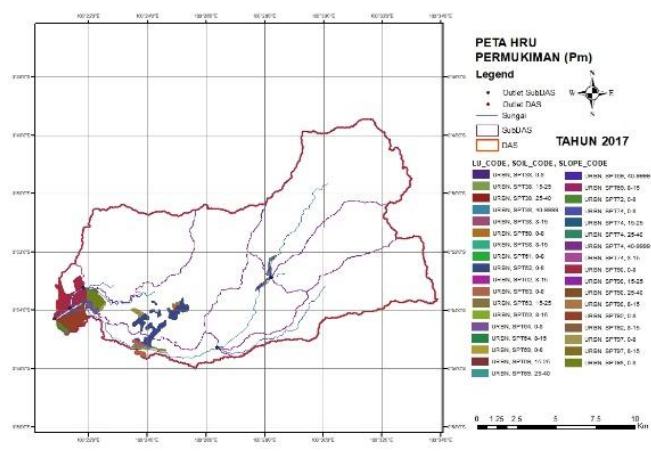

Gambar 24. Peta HRU pemukiman pada tahun 2017
Bertambahnya luas lahan kering sebagian besar berasal dari berubahnya lahan hutan, semak, dan sawah menjadi lahan kering yang letaknya dekat dengan lahan kering tersebut. Perubahan lahan hutan disebabkan karena terjadinya perubahan lahan hutan menjadi semak dan lahan kering. Perubahan lahan semak terjadi karena berubahnya lahan semak menjadi pemukiman, sawah, dan lahan kering. Sedangkan bertambahnya lahan sawah berasal dari lahan kering dan semak. Terlihat cukup jelas perubahan tataguna lahan dari tahun 2009 sampai tahun 2017.

Analisis HRU dibagi berdasarkan penutup lahan yang digunkanan. Hal ini dilakukan agar dapat dilihat pengaruh perubahan lahan terhadap perubahan yang terjadi pada HRU. HRU dapat menganalisa kemiringan, jenis tanah, dan lahan yang ada pada suatu DAS yang ditinjau.

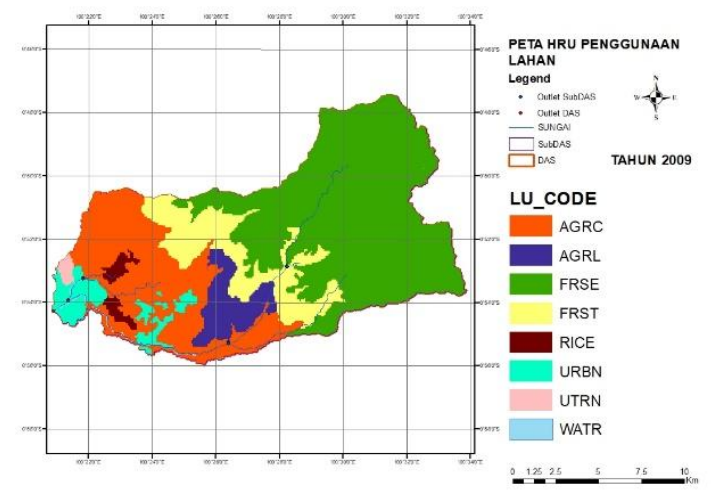

Gambar 25. Peta HRU pengunaan lahan tahun 2009

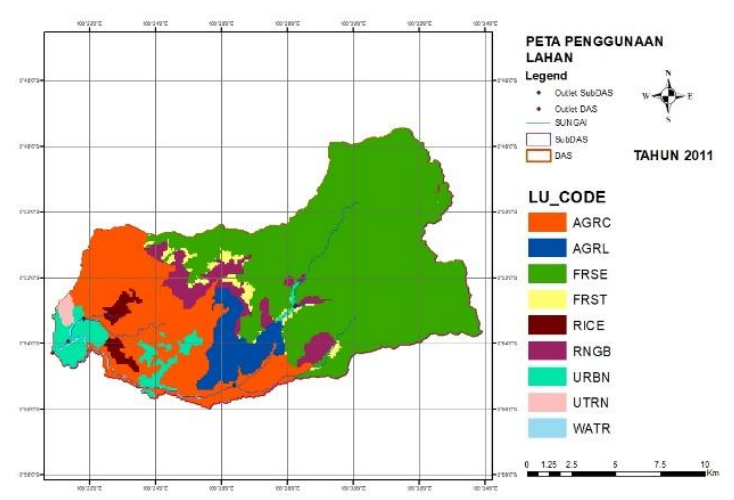

Gambar 26. Peta HRU pengunaan lahan tahun 2011 


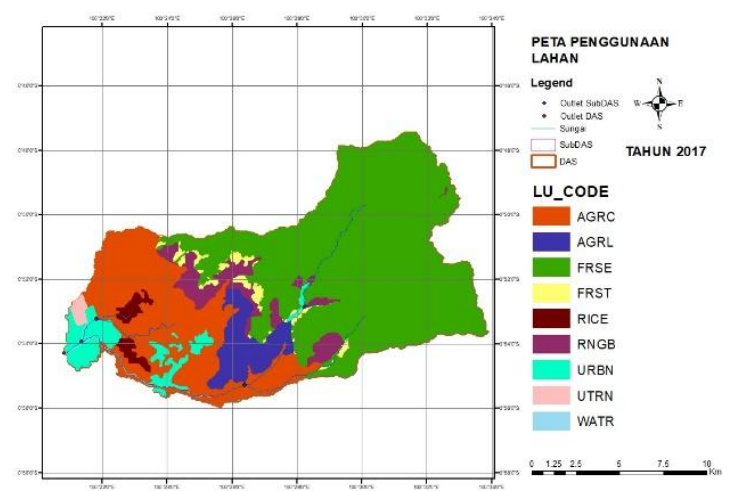

Gambar 27. Peta HRU pengunaan lahan tahun 2017

Tabel 2. Jumlah HRU, HRU pada subDAS tahun 2009-2017 di DAS Batang Kuranji

\begin{tabular}{|c|c|c|c|c|c|c|c|c|c|}
\hline \multirow{2}{*}{$\begin{array}{l}\text { SUB } \\
\text { DAS }\end{array}$} & \multicolumn{3}{|c|}{ Jumlah HRU } & \multicolumn{3}{|c|}{$\begin{array}{c}\text { HRU Dominan } \\
\text { (penutup lahan/tanah/kemiringan) }\end{array}$} & \multicolumn{3}{|c|}{$\frac{\text { Luas HRU Dominan }}{(\mathrm{Ha})}$} \\
\hline & 2009 & 2011 & 2017 & 2009 & 2011 & 2017 & 2009 & 2011 & 201 \\
\hline 1 & 28 & 43 & 40 & FRSE/SPT38/40-9999 & FRSE/SPT38/40-9999 & FRSE/SPT38/40-9999 & 2317.47 & 2335.23 & 2334 \\
\hline 2 & 30 & 35 & 38 & FRSE/SPT38/40-9999 & FRSE/SPT38/40-9999 & FRSE/SPT38/40-9999 & 899.25 & 948.02 & 948. \\
\hline 3 & 60 & 77 & 73 & AGRC/SPT98/0-8 & AGRC/SPT98/0-8 & AGRC/SPT59/0-8 & 762.43 & 762.43 & 673. \\
\hline 4 & 111 & 126 & 127 & FRSE/SPT38/40-9999 & FRSE/SPT38/40-9999 & FRSE/SPT38/40-9999 & 601.47 & 666.78 & 668. \\
\hline 5 & 9 & 10 & 20 & URBN/SPT90/0-8 & \begin{tabular}{|l|} 
URBN/SPT90/0-8 \\
\end{tabular} & URBN/SPT90/0-8 & 186.43 & 186.43 & 188. \\
\hline 6 & 20 & 20 & 20 & URBN/SPT92/0-8 & URBN/SPT92/0-8 & URBN/SPT92/0-8 & 130.52 & 130.52 & 140. \\
\hline 7 & 89 & 125 & 125 & FRST/SPT38/25-40 & FRSE/SPT38/25-40 & FRSE/SPT38/25-40 & 159.65 & 197.52 & 194. \\
\hline 8 & 68 & 72 & 70 & FRSE/SPT38/40-9999 & FRSE/SPT38/40-9999 & FRSE/SPT38/40-9999 & 1565.84 & 1634.34 & 1634 \\
\hline 9 & 72 & 72 & 69 & AGRC/SPT63/0-8 & AGRC/SPT63/0-8 & AGRC/SPT63/0-8 & 241.02 & 241.02 & 239 \\
\hline
\end{tabular}

Pada tahun 2009-2017, perubahan HRU yang paing dominan terjadi pada subDAS 6. Hal ini terjadi karena meningkatnya pertumbuhan pemukiman di daerah tersebut. Pemukiman meningkat sebesar $10 \%$ dalam periode 3-5 tahun sekali. Pada subDAS 1, luas hutan primer juga berkurang rentang tahun 2009-2017. Ini diakibatkan oleh banyaknya masyarakat yang membebaskan beberapa persen lahan menjadi perumahan akibat isu tsunami pasca gempa tahun 2009. Pada umumnya DAS Batang Kuranji bagian hulu dominannya adalah hutan hijau, hutan campur, dan sawah, dan lahan pertanian kering campur semak. Sedangkan pada daerah hilir dan muara didominasi oleh pemukiman dan transportasi. Pada subDAS 8 juga mengalami penurunan terhadap luas lahan hutan campuran.

Berdasarkan tabel di atas, beberapa subDAS juga mengalami perubahan- perubahan tataguna lahan yang tidak begitu signifikan. Hal ini terkait dengan perubahan tataguna lahan yang terjadi, yang mengakibatkan perubahan pola spasial HRU di wilayah tersebut. Berubahnya pola spasial tersebut juga menyebabkan berubahnya HRU dominan dan luasnya. Perubahan HRU yang paling banyak terjadi pada 2009-2017 pada subDAS 3, 6 dan 9. Yang mana pada subDAS 3 pada tahun 2009-2011 didominasi oleh pertanian lahan kering campur semak. Namun pada tahun 2017 terjadi perubahan pertanian lahan kering, semak belukar, dan pemukiman. Pada subDAS 6 terjadi peningkatan terhadap luas pemukiman, sedangkan pada subDAS 9 pada tahun 2009-2011 lahan tersebut merupakan lahan pertanian kering campur semak.

\section{Simulasi Aliran Permukaan dan Debit Menggunakan SWAT}

Tabel 3. Akumulasi aliran permukaan $\left(Q_{\text {surf }}\right)$ tahun 2009 - 2017 pada setiap subDAS

\begin{tabular}{|c|c|c|c|c|c|c|c|c|c|}
\hline \multirow{2}{*}{ Sub DAS } & \multicolumn{3}{|c|}{ Aliran permukaan (QSURF) } & \multicolumn{3}{c|}{ Perubahan (OSURF) } & \multicolumn{3}{c|}{ Perubahan (\%) } \\
\cline { 2 - 11 } & 2009 & 2011 & 2017 & $2009-2011$ & $2011-2017$ & $2009-2017$ & $2009-2011$ & $2011-2017$ & $2009-2017$ \\
\hline 1 & 65.174 & 64.812 & 64.748 & -0.362 & -0.064 & -0.426 & -0.556 & -0.099 & -0.654 \\
\hline 2 & 75.427 & 75.360 & 75.318 & -0.067 & -0.042 & -0.109 & -0.089 & -0.056 & -0.145 \\
\hline 3 & 82.169 & 82.352 & 82.564 & 0.183 & 0.213 & 0.396 & 0.223 & 0.258 & 0.481 \\
\hline 4 & 84.181 & 83.798 & 83.500 & -0.383 & -0.298 & -0.681 & -0.455 & -0.355 & -0.8009 \\
\hline 5 & 31.918 & 31.918 & 31.969 & 0.000 & 0.051 & 0.051 & 0.000 & 0.161 & 0.161 \\
\hline 6 & 41.040 & 41.040 & 44.881 & 0.000 & 3.842 & 3.842 & 0.000 & 0.361 & 0.361 \\
\hline 7 & 88.066 & 86.621 & 86.560 & -1.445 & -0.061 & -1.506 & -1.641 & -0.070 & -1.710 \\
\hline 8 & 57.405 & 57.282 & 57.257 & -0.123 & -0.025 & -0.148 & -0.214 & -0.044 & -0.258 \\
\hline 9 & 96.911 & 96.911 & 96.955 & 0.000 & 0.044 & 0.044 & 0.000 & 0.046 & 0.046 \\
\hline Rata-2atata & 69.143 & 68.899 & 69.306 & -0.244 & 0.407 & 0.163 & -0.303 & 1.022 & 0.719 \\
\hline
\end{tabular}


Bila dilihat perubahan berdasarkan masing-masing subDAS pada tahun 2009 2017, kenaikan aliran permukaan secara linier pada subDAS 3, 5, 6, dan 9. Hal ini karena terjadinya penambahan akumulasi aliran permukaan pada subDAS pada ahun 2009 - 2017. Sedangkan aliran permukaan secara fluktuatif terjadi pada subDAS 1, 2, 4, 7, dan 8. Hal ini terjadi karena penurunan dan kenaikan akumulasi aliran permukaan pada tahun 2009 - 2017 di subDAS tersebut. Perubahan akumulasi aliran permukaan ini terjadi akibat adanya perubahan HRU pada masing-masing subDAS. Dengan demikian, HRU dominan dan luas HRU dominan tersebut pada suatu subDAS mempengaruhi akumulasi aliran permukaan di subDAS tersebut.

Debit aliran masing-masing subDAS dapat dilihat pada tabel 4. Pada tabel tersebut terlihat bahwa semakin jauh jarak subDAS ke outlet, debit alirannya semakin kecilsehingga subDAS yang memiliki debit aliran yang paling kecil adalah subDAS 1.sebaliknya, semakin dekat jarak subDAS ke outlet debit alirannya semakin besar, yaitu pada subDAS 9. Selain pada itu subDAS 9 sebagian besar terdiri dari pemukiman dan transportasi. Daerah tersebut merupakan daerah kawasan Ulak Karang.

Tabel 4. Perubahan debit aliran tahun 2009 - 2017 pada subDAS

\begin{tabular}{|c|c|c|c|c|c|c|c|c|c|}
\hline \multirow{2}{*}{ Bulan } & \multicolumn{3}{|c|}{ Debit Aliran $\left(\mathrm{m}^{\prime} \mathrm{3} / \mathrm{s}\right)$} & \multicolumn{3}{|c|}{ Perubahan $\left(\mathrm{m}^{3} 3 / \mathrm{s}\right)$} & \multicolumn{3}{|c|}{ Perubahan $(\%)$} \\
\hline & 2009 & 2011 & 2017 & $2009-2011$ & 2011-2017 & 2009-2017 & $2009-2011$ & 2011-2017 & $2009-2017$ \\
\hline 1 & 5.82 & 5.83 & 5.84 & 0.01 & 0.01 & 0.02 & 0.00 & 0.16 & 0.27 \\
\hline 2 & 23.59 & 23.58 & 23.61 & -0.01 & 0.03 & 0.02 & 0.00 & 0.12 & 0.07 \\
\hline 3 & 22.81 & 22.80 & 22.83 & -0.01 & 0.02 & 0.02 & 0.00 & 0.11 & 0.08 \\
\hline 4 & 34.67 & 34.67 & 34.73 & 0.00 & 0.06 & 0.06 & 0.00 & 0.16 & 0.16 \\
\hline 5 & 14.34 & 14.34 & 14.35 & 0.00 & 0.02 & 0.02 & 0.00 & 0.12 & 0.11 \\
\hline 6 & 25.35 & 25.38 & 25.40 & 0.02 & 0.03 & 0.05 & 0.00 & 0.10 & 0.20 \\
\hline 7 & 37.72 & 37.68 & 37.75 & -0.04 & 0.06 & 0.03 & 0.00 & 0.17 & 0.07 \\
\hline 8 & 12.54 & 12.48 & 12.85 & -0.06 & 0.37 & 0.31 & 0.00 & 2.98 & 2.49 \\
\hline 9 & 12.93 & 12.83 & 12.85 & -0.10 & 0.02 & .0 .08 & -0.01 & 0.18 & -0.60 \\
\hline 10 & 15.48 & 15.41 & 15.29 & -0.07 & -0.12 & -0.19 & 0.00 & -0.81 & -1.23 \\
\hline 11 & 14.84 & 14.81 & 14.81 & -0.03 & 0.00 & -0.03 & 0.00 & 0.01 & -0.19 \\
\hline 12 & 32.64 & 32.67 & 32.66 & 0.02 & -0.01 & 0.02 & 0.00 & -0.03 & 0.05 \\
\hline
\end{tabular}

\section{Analisis Debit Andalan}

Untuk menghitung debit andalan pada DAS Batang Kuranji, digunakan dua stasiun curah hujan yaitu stasiun Gunung Nago dan stasiun Batu Busuak. Masingmasing menggunakan periode 10 tahun, data curah hujan yang digunakan yaitu curah hujan maksimum perlimabelas hari pada tahun 2008 sampai dengan tahun 2017. Sedangkan untuk permodelan debit pada SWAT dibutuhkan data curah hujan harian.

Selanjutnya, data yang dibutuhkan adalah data cuaca/temperatur, kelembaban udara, kecepatan angin, dan penyinaran matahari yang mana akan mempengaruhi kondisi hidrologi suatu DAS. Cuaca dapat diartikan sebagai keadaan atmosfer pada suatu saat dan sifatnya selalu berubahubah, sedangkan iklim dapat diartikan sebagai keadaan cuaca rata-rata dalam periode lama.

Analisis data yang dilakukan secara manual yaitu menghitung evapotranspirasi $\left(E T_{0}\right)$ dengan menggunakan metode Penman Modifikasi. Dengan rumus:

$E T_{0}=c \times[W \times R n+(1-W) \times f(U) \times$ $(e s-e a)](3)$

Lalu dilanjutkan dengan menghitung debit andalan menggunakan metode FJ Mock. Metode ini cocok digunakan untuk daerah yang memiliki curah hujan yang cukup tinggi seperti Sumatera Barat.

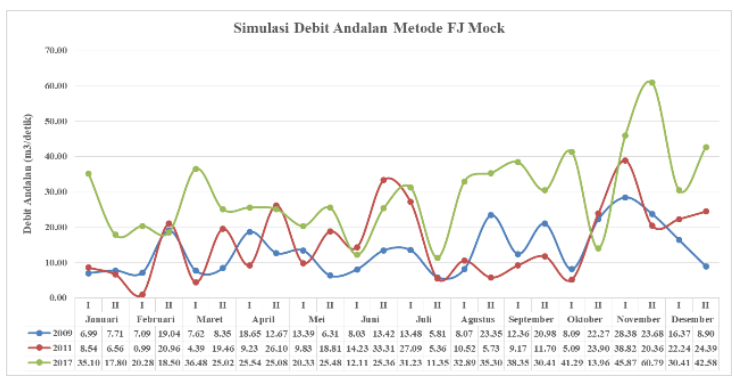

Gambar 28. Grafik simulasi debit andalan metode FJ. Mock 


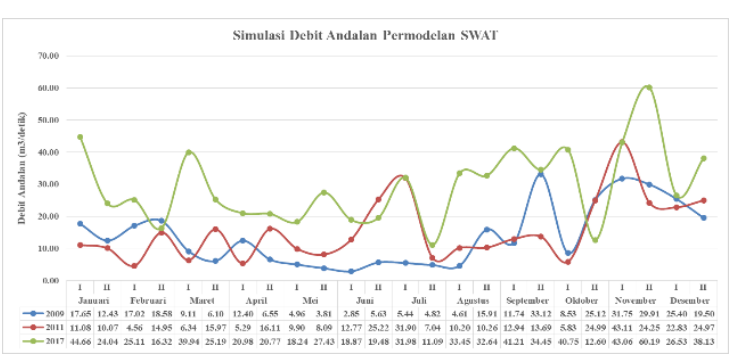

Gambar 29. Grafik simulasi debit andalan permodelan SWAT

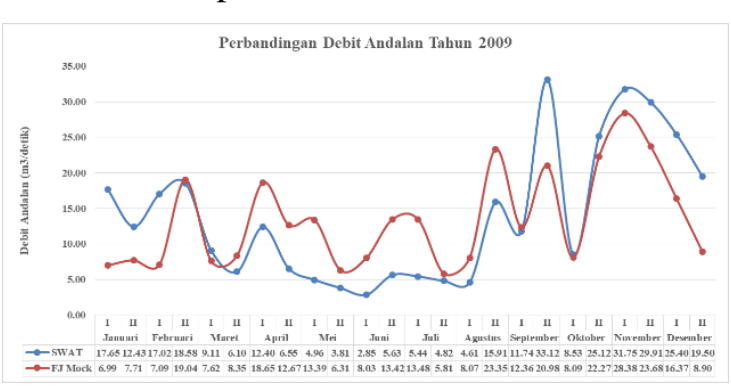

Gambar 30. Grafik debit andalan metode FJ.

Mock dengan SWAT tahun 2009

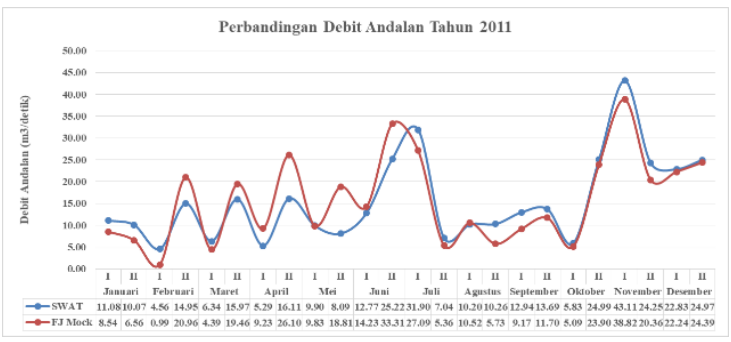

Gambar 31. Grafik debit andalan metode FJ.

Mock dengan SWAT tahun 2011

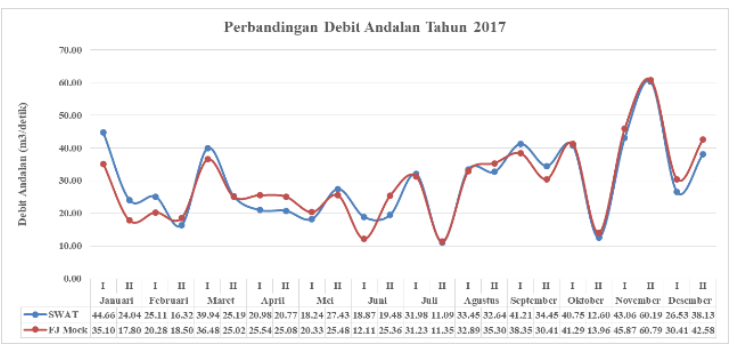

Gambar 32. Grafik debit andalan metode FJ. Mock dengan SWAT tahun 2017

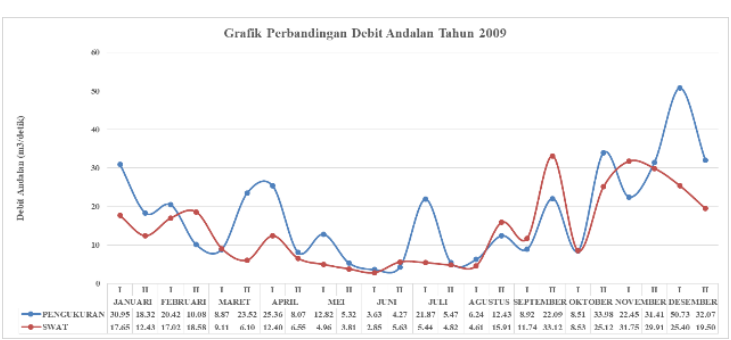

Gambar 33. Grafik debit pengukuran dengan SWAT tahun 2009

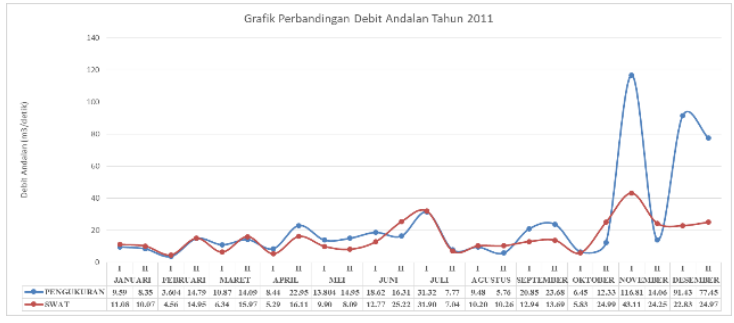

Gambar 34. Grafik debit pengukuran dengan SWAT tahun 2011

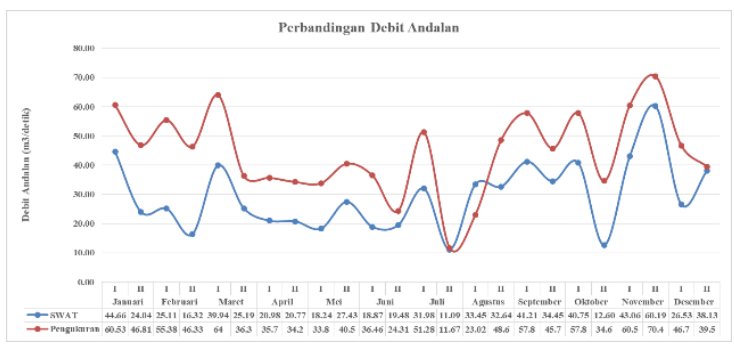

Gambar 35. Grafik debit pengukuran dengan SWAT tahun 2017

\section{SIMPULAN}

1. Pada analisa unit respon hidrologi (HRU), untuk tanah pada DAS Batang Kuranji didominasi oleh kedalaman tanah (solum) mencakup horizon A dan B. Itu artinya bahwa kapasitas penyimpanan air pada tanah DAS tersebut mempunyai kapasitas sangat dalam. Untuk kemiringan DAS, pada daerah hulu DAS terdapat perbukitan dengan kemiringan antara 25-40\% dan ada juga kemiringan $>40 \%$.

2. Untuk sebaran penggunaan lahan, DAS Batang Kuranji didominasi oleh hutan lindung di bagian hulu. Sedangkan di daerah hilir berupa pertanian lahan kering, sawah, dan pemukiman. Perubahan tataguna lahan pada DAS Batang Kuranji itu mengalami perubahan yang tidak terlalu signifikan di bagian hulu. Karena pada tahun 2009 kawasan hutan lindung pada bagian hulu DAS memiliki persentase luas sebesar $62 \%$.

3. Pada tahun 2009-2017, perubahan jumlah dan luas HRU mempengaruhi akumulasi aliran permukaan dan debit andalan secara temporal. Hal ini 
disebabkan oleh koefisien runoff yang meningkat akibat perubahan penggunaan lahan pada DAS Batang Kuranji. Kenaikan koefisien setiap tahunnya bisa mencapai 0,1 .

4. Untuk perbandingan debit andalan dengan SWAT dan metode FJ. Mock, diteliti dengan cara mendapatkan nilai Nash-Sutcliffe (NS) berdasarkan rumus pada persamaan (3.3), NS diperoleh sebesar 0,6 - 0,8. Artinya simulasi debit andalan pada SWAT tersebut bisa dikatakan memuaskan.

\section{DAFTAR PUSTAKA}

[1] Arnold JG, Kiniry JR, Srinivasan R, Williams JR, Haney EB, Neitsch SL. 2011. Soil and Water Assessment Tool : Input/Output File Documentation Version 2009. Texas: Agricultural Research Serviceand Texas AgriLife Research.

[2] Asdak, C., 2000 : Hidrologi dan Pengelolaan Daerah Aliran Sungai, UGM Press, Yogyakarta.

[3] Emiyati. 2012. Hydrologic Response Unit (HRU) dan Debit Aliran Ci Rasea. Tesis. Depok: Universitas Indonesia.

[4] Firdaus, Gunadi. 2014. Analisis Respon Hidrologi Terhadap Penerapan Teknik Konservasi Tanah di Sub DAS Lengkong Menggunakan Model SWAT. Tesis. Bogor: Institut Pertanian Bogor.

[5] Gassman PW, Reyes M, Green $\mathrm{CH}$, Arnold JG. 2007. The Soil and Water Assessment Tool: Historical Development, Applications, And Future Research Directions. America: Journal of American Society of Agricultural And Biological Engineers ISSN 0001-2351.
[6] Hadisusanto, Nugroho. 2010. Aplikasi Hidrologi. Malang: Jogja Mediautama.

[7] Irsyad, Fadli. 2011. Analisis Debit Sungai Cidanau dengan Aplikasi SWAT. Tesis. Bogor: Institut Pertanian Bogor.

[8] Linsley, K, dkk. 1982. Hydrology for Engineers. Terjemahan oleh Yandi Hermawan. 1996. Jakarta: Penerbit Erlangga.

[9] Neitsch, S.L, J.G. Arnold, J.R. Kiniry, J.R. Williams. 2005. Soil and Water Assessment Tool Theoretical Documentation Version 2005. Texas: Agricultural Research Service and Texas Agricultural Experiment Station.

[10] Rahayu, S. dkk. 2009. Monitoring Air di Daerah Aliran Sungai. ICRAF Asia tenggara.

[11] Rau, Ibrahim Maulana. 2012. Analisis Debit Sungai dengan Menggunakan Model SWAT Pada DAS Cipasauran, Banten. Skripsi. Bogor: Institut Pertanian Bogor.

[12] Soewarno. 2000. Hidrologi Operasional Jilid Kesatu. Bandung: PT. Citra Aditya Bakti.

[13] Sosrodarsono, Suyono, dan Kensaku Takeda. 1978. Hidrologi Untuk Pengairan. Jakarta: PT. Pradnya Paramita.

[14] Subarkah, Iman. 1980. Hidrologi Untuk Perencanaan Bangunan Air. Bandung: Idea Dharma.

[15] Triadmodjo, Bambang. 2008. Hidrologi Terapan. Yogyakarta: Beta Offset. 